\title{
Multicultural ethics in rehabilitation services
}

\author{
Tammy Jorgensen Smith* \\ University of South Florida, College of Behavioral and Community Sciences, Department of Rehabilitation and \\ Mental Health Counseling, Tampa, Florida, USA
}

Received 20 January 2021

Accepted 20 January 2021

\begin{abstract}
.
BACKGROUND: Rehabilitation professionals are required to be competent in serving multiculturally diverse individuals in a manner that promotes empowerment and full engagement. Multicultural competency is critical for accurate clinical assessment and diagnosis and for effectively serving a diverse population of clients.

OBJECTIVE: The major objective of this paper is to promote multicultural competency and sensitivity by increasing knowledge and awareness of ethical considerations for multicultural populations in rehabilitation settings.

CONCLUSION: Diagnostic tools and ethical decision-making models that integrate multicultural considerations are discussed, and recommendations for building multicultural competency are provided.
\end{abstract}

Keywords: Multicultural competency, diversity, rehabilitation counseling, ethical decision-making models

\section{Introduction}

Approximately 328 million individuals, 50.8\% female, reside in the United States. White individuals represent $76.3 \%$ of the total population, followed by Hispanic/Latino (18.5\%), Black/African American (13.4\%), Asian (5.9\%), two or more races (2.8\%), American Indian/Alaska Native (1.3\%) and Pacific Islander (0.2\%) (U.S. Census Bureau, 2021). The census indicates $13.6 \%$ of the population is foreign born and $21.6 \%$ of families speak a language other than English at home. Individuals with disabilities under the age of 65 total $8.6 \%$ of the population and just over $10 \%$ of persons in the U.S. live in poverty.

An article by Frey (2020) presents race-ethnic population estimates that were released by the U.S. Census Bureau in advance of the 2020 census. The data support similar projections of a more diverse

\footnotetext{
*Address for correspondence: Tammy Jorgensen Smith, Ph.D., CRC, Associate Professor, University of South Florida, College of Behavioral and Community Sciences, Department of Rehabilitation and Mental Health Counseling, Tampa, Florida USA. Tel.: +813 974 0973; Fax: +813 974 8080; E-mail: smithtj@usf.edu.
}

nation in which the White population will drop below $50 \%$ of the total U.S. population within the next 25 years (Budiman, 2020; Horowitz, 2019; Poston, 2020). The 2010-2020 decade was the first in U.S. history to show a decrease in the White population (Frey, 2020). During the same timeframe, the number of Latino/Hispanic individuals in the U.S. grew by $20 \%$, Asian Americans by $29 \%$, and Black Americans by $8.5 \%$. Most notably, the previously small number of individuals who identify as two or more races grew by $30 \%$ (Frey, 2020).

Poston (2020) reports there are over 74 million people under the age of 18 in the U.S. and over 56 million people age 65 and older. He asserts, ten years from now, the number of elder adults will come close to the number of young adults. This is due, in part, to aging baby boomers but is also due to longer life expectancy and a reduction in the number of births. Currently, millennials make up the majority of the adult population and youth in Generation Z (those born after 1996) are now beginning to enter adulthood. Approximately $48 \%$ of Generation $\mathrm{Z}$ are racial or ethnic minorities (Cilluffo \& Cohn, 2019). 


\section{Diversity and multiculturalism}

Diversity is defined as real or perceived differences between people that include but are not limited to race, ethnicity, age, gender, disability, religion, personality, sexual orientation, and socioeconomic status (What's the Difference Between a Diverse and a Multicultural World? 2014). Multiculturalism is similar, but more complex than diversity. It focuses on inclusiveness, respect, understanding, and acknowledgement of how power in society can be unequal due to race, gender, sexual orientation, power, and privilege (Diversity and Multiculturalism, 2016). In a diverse world, people acknowledge the differences that exist among individuals. In a multicultural world, people accept and embrace the differences of others.

The literature indicates rehabilitation counselors both need and want a broader knowledge base and skillset to prepare them to work with a diverse clientele (Beveridge et al., 2016; Zanskas \& Leahy, 2007). A study by Beveridge et al. (2016) found multicultural competence to be one of the most significant training needs for rehabilitation counselors with $67 \%$ agreement from respondents. In response, rehabilitation counseling programs must adapt their curricula to ensure students are provided with the knowledge and skills necessary to provide high quality services that are culturally responsive and sensitive. Beveridge et al. (2016) state, "A diverse clientele elicits an increased complexity in the rehabilitation counseling process. For example, clients' identification with their disability can be affected by another cultural identity, such as ethnicity, socioeconomic status, gender, and sexual orientation" (p. 214).

This article provides information intended to increase the multicultural awareness and knowledge of rehabilitation professionals to prepare them to serve a diverse clientele in a culturally responsible manner. Ethical considerations are presented along with a transcultural ethical decision-making model that incorporates concepts from multicultural theory and builds upon other commonly utilized ethical resolution models. Information for integrating cultural competency education into rehabilitation counselor training curricula is included.

\section{Cultural identity}

Every human is multicultural. Our cultural identity is made up of a combination of varying factors including our experiences, geographical location, socio-political history, and many other elements of culture that make each of us unique. Multidimensional characteristics that make up an individual's cultural identity include ancestry, ethnicity, age/generation, gender/gender identity, sexual orientation, disability status, language, education, profession, marital status, religion and/or spirituality, family composition, political attitudes, socioeconomic status, and social class among other variables (Lee \& Matteliano, 2009).

\section{Iceberg concept of culture}

In 1976, Edward T. Hall first introduced an iceberg analogy to explain the concept of culture. He noted that only about $10 \%$ of an iceberg can be seen while $90 \%$ of it is hidden beneath the water. Many aspects of a person's cultural identity are not immediately recognizable. The majority of what we see when we first meet a person is surface culture - the visible tip of the iceberg. Surface culture is observable and objective. It includes behaviors, traditions, and customs such as language, greetings, food, clothing, and music (Anon, 2021).

Culture is interconnected with our sense of identity and self- understanding. Some may not even be aware of how culture influences our value system and shapes our worldview, relationships, and perceptions (Culbertson, 2021). To truly know a person, one must go below the surface to the level of deep culture. Deep culture includes internal, unconscious, subjective, and implicitly learned constructs that include a person's core values, beliefs, priorities, and assumptions (Anon, 2021). Deep culture encapsulates worldview, body language, gender roles, and concepts of time, space, justice, authority, and power. Rehabilitation counselors who take the time to explore an individual's deep culture may be more successful in developing rapport and trust necessary to facilitate the best rehabilitation outcomes.

\section{Cultural competence}

Multiculturally competent counseling services require continual "refinement, development, and validation based on continuing and new sociocultural and political issues that impinge on the lives of individuals and families" (Arredondo \& Toporek, 2004, p. 50). According to Hays and Erford (2018), multiculturally competent professionals consider the influence of 
family, community, and other environmental factors on the lives of both the professional and the client. Becoming multiculturally competent is "a journey that lasts an entire professional career" (p. 35).

Three dimensions of cultural competency in counseling are: 1) awareness of one's own attitudes, values, biases, and assumptions; 2) knowledge of ways in which cultural processes affect different groups including understanding others' worldviews without judgement; and 3) development of culturally appropriate approaches and skills including application of effective therapeutic strategies that consider the client's cultural identity and worldview (AMCD, 2015).

The first step toward cultural competence is being culturally aware. This involves understanding your own cultural identity and recognizing underlying biases. Rehabilitation professionals must assess their own cultural background and experiences to better understand the influence it has on their attitudes, values and biases toward others, disability, and their role in the rehabilitation process. The goal of cultural awareness is to develop respect for the differences of others and to recognize and appreciate the limits of one's multicultural competency to be able to best serve a diverse clientele (Hays \& Erford, 2018; Lee \& Matteliano, 2009).

In addition to developing self-awareness and knowledge of one's own cultural influences, rehabilitation professionals must acquire knowledge of the cultures of those they serve. As mentioned, to be fully knowledgeable about a culture, one must delve beyond surface culture into deep culture. This may be accomplished by engaging in meaningful interactions with diverse people and groups. These activities also facilitate an understanding of the similarities and differences within and between cultural groups (Hays \& Erford, 2018; Lee \& Matteliano, 2009; AMCD, 2015).

Cultural knowledge leads to cultural sensitivity which refers to the way people view those who are culturally different from themselves. A culturally sensitive person embodies genuineness, acceptance, and respect for others (Papadopoulos et al., 1998). Words and actions reflect cultural sensitivity as does the ability to recognize other's perspective and experience. Hays and Erford (2018) assert that multiculturally sensitive approaches consider the "intricacies of cross-cultural communication" including verbal communication and the use of language and metaphors, non-verbal communication to include proxemics, kinesics, and paralanguage, and emotional expression (p.35). Experiences involving prejudice, discrimination, immigration, acculturation, and other contextual factors such as stereotypes, stigma, and mistrust must be considered and addressed as part of a multiculturally sensitive and appropriate approach to rehabilitation counseling services.

Cultural competence requires synthesis and application of cultural awareness, knowledge, and sensitivity. Once this foundation is in place, rehabilitation professionals must translate multicultural knowledge into practice. According to Lee \& Matteliano (2009), "skills emanate from metacognitive awareness and academic foundation, but are operationalized through interaction with individuals from multicultural backgrounds and through supervision from colleagues" (p. 38). At the basic level, professionals must learn to assess each person's cultural identity, incorporate their worldview, and utilize culturally relevant and appropriate intervention techniques and strategies (AMCD, 2015; Hays \& Erford, 2018; Lee \& Matteliano, 2009). In doing so, one must recognize the limits of one's competencies to know when referral, consultation, and/or further education is warranted (Lee \& Matteliano, 2009). Additional actions of culturally competent professionals may include social justice and advocacy efforts including challenging inequality and taking action to become part of the solution for addressing acts of prejudice, oppression, and discrimination (Hays \& Erford, 2018; Lee \& Matteliano, 2009).

\section{Key concepts related to culture and cultural competence}

\subsection{Worldview}

Worldview refers to a person's personal philosophy of life and conceptualization of his or her relationship with the world (Hays \& Erford, 2018). It is the cultural lens or viewpoint through which the individual sees the world. To work with diverse clientele most effectively, a rehabilitation professional must first take the time to view the world from the perspective of each individual with whom they work. This is the epitome of empathy or putting oneself in another's shoes. Professionals who try to work with people through their own cultural lens may miss key influential factors beginning with the ability to build rapport. They may misinterpret verbal and non-verbal communication, approach topics from an individualistic standpoint with clients from collectivist cultures, 
and/or offend people through lack of cultural awareness - all which impact the ability to reach optimal outcomes.

\subsection{Collectivism}

Collectivism is a cultural value that encourages togetherness and giving priority to the family or community rather than the individuals in the group (Hays \& Erford, 2018). Although the United States is prominently an individualistic country, most of the world's countries and people are collectivistic. Individualistic societies tend to value autonomy, self-determination, and competitiveness. The United States, Canada, England, Australia, and New Zealand, mostly English-speaking countries, are the most individualistic countries. The rest of the countries of the world primarily adhere to collectivist values and behaviors (Steemit, 2021). It is important to assess this element of cultural identity, and each person's acculturation level, to best work with individuals and their families. Acculturation refers to the "degree to which immigrants identify with and conform to the new culture of a host society, or the degree to which they integrate new cultural values into their current value system" (Hays \& Erford, 2018, p. 23).

\subsection{Microaggressions}

Microaggressions are defined as the everyday, subtle interactions or behaviors that communicate bias toward historically marginalized groups (Limbong, 2020). These may be communicated verbally or nonverbally. Psychology Professor and author, Kevin Nadal, in an interview with National Public Radio (Limbong, 2020), stated the difference between microaggressions and discrimination or macroaggressions is that people who commit microaggressions might do so unconsciously. A few examples of microaggressions are assuming a person has a cognitive disability based on appearance or speech, speaking in a condescending tone with elders, assuming a superior (I am the expert) stance, and asking a person "What are you?" in reference to his or her race and ethnicity. Becoming aware of microaggressions is the first step toward eliminating them and their negative effects.

\section{Diagnosis and assessment}

Knowledge of culturally appropriate diagnostic, assessment, and intervention methods is critical for serving individuals from diverse backgrounds. Many times, diagnoses do not reflect the cultural elements that may influence them. The standard diagnostic system in the U.S. is primarily grounded in the knowledge of White men (Hays \& Erford, 2018). It does not account for culture-bound syndromes, collectivist beliefs, or verbal and non-verbal communication differences. Additionally, many research studies that inform diagnoses are based on non-diverse participant samples. To compensate for these shortcomings, professionals should consult with multiple sources, with consideration of cultural influences, prior to making a diagnosis.

Without culturally appropriate, holistic assessment, people tend to be diagnosed or labeled based on a brief interaction. Rarely do first impressions truly show who a person is and what experiences and circumstances influence how they interact with the environment and others. Rehabilitation professionals must know when to leave traditional assessment procedures aside and take the time to listen to individuals describe their issues in their own words and ask good questions to best understand how to help (Griswold et al., 2007).

When determining what assessments to use to learn more about a person, check to see if the tool was normed with people from the client's cultural group(s). It may be necessary to adapt methods of assessment and/or identify culturally relevant assessments to meet the needs of diverse clientele (Lee $\&$ Matteliano, 2009). Otherwise, the results of the assessment may provide inaccurate information. Culture may also impact the way test results are interpreted. Not recognizing these potential issues may result in misdiagnosis and treatment strategies that incorporate inappropriate interventions.

\section{Multicultural ethics}

Ethics are moral principles that govern a person's behavior and choices. Most professions are guided by a code of ethics by which members must abide. In rehabilitation services, Certified Rehabilitation Counselors (CRC) must abide by the corresponding CRC code of ethics. The most current version of the Code of Professional Ethics for Rehabilitation Counselors integrates multicultural considerations throughout its standards with specific standards that are focused on respecting diversity and culture, non-discrimination, avoiding value imposition, advocacy, attitudinal barriers, cultural competency, and 
diversity (CRCC, 2017). Section A.2. requires rehabilitation counselors to "demonstrate respect for the cultural identity of clients in developing and implementing rehabilitation and treatment plans and providing and adapting interventions" (p. 4). Section D.2. specifically addresses cultural competency and diversity. Rehabilitation counselors are expected to "develop and maintain knowledge, personal awareness, sensitivity, and skills and demonstrate a disposition reflective of a culturally competent rehabilitation counselor working with diverse client populations" (p. 14). Interventions and services must consider cultural perspectives and professionals are responsible for addressing barriers that may interfere with achieving effective rehabilitation outcomes (CRCC, 2017).

Counselors are also guided by the code of ethics of the American Counseling Association (ACA). ACA's core professional values of the counseling profession include “... honoring diversity and embracing a multicultural approach in support of the worth, dignity, potential, and uniqueness of people within their social and cultural contexts" (ACA, 2014, p. 3). For all counseling professionals, ethical codes prohibit discrimination based on factors including age, disability, sex, race, ethnicity, religion, socioeconomic status, sexual orientation, or any other difference of the client from the mainstream (ACA, 2014). Rehabilitation counselors must be cognizant of therapeutic relationship dynamics including real and perceived power differential and the potential for their values to be imposed upon individuals they serve (Beveridge et al., 2016).

\section{Ethical decision-making models}

Ethical decision-making models were developed to provide an analytical and strategic approach to making decisions. They ensure that decisions are grounded in reason and document the process of making an ethical choice. In the ACA's Practitioner's Guide to Ethical Decision Making (Forester-Miller \& Davis, 2016), the authors state "There is rarely one right answer to a complex ethical dilemma. However, if you follow a systematic model, you can be assured that you will be able to give a professional explanation for the course of action you chose." (p. 5).

To date, most ethical decision-making models in the counseling field provide minimal reference to culture or how to integrate culture, systematically, into the ethical decision-making process.
Common categories for ethical decision-making models include rational models based on principles, virtue models based on moral ethics, socialconstructivist models based on cognition theory, collaborative models that are relational and based on group perspective, and the model that we will focus on, the transcultural integrative model (Garcia et al., 2003). As we briefly cover the models, you will see how they build upon one another leading to the most comprehensive approach to ethical decision making.

\subsection{Rational/ principle ethics model}

The Rational Model for ethical decision making is based upon rules and directives that guide actions. The model includes consideration of six duties of principle ethics: 1) autonomy or one's right to self-determination; 2) nonmaleficence which encapsulates the principle of do no harm; 3 ) beneficence which refers to the well-being of clients; 4) justice, or the concept of fairness; and 5) fidelity which refers to the professional's duty to respect and fulfill obligations in a trustworthy manner (Kitchener, 1984). The Rational Model's 7-step linear process is outlined in the ACA's guide to ethical decision making (Forester-Miller \& Davis, 2016). A primary strength of the model is that it utilizes a systematic, critical-evaluative level of analysis of the dilemma as guided by specific ethical principles, standards, and laws (Garcia et al., 2003). However, cultural variables are not considered in the analysis of the dilemma.

\subsection{Virtue/ moral ethics model}

In virtue or moral ethics, emphasis is on personal qualities including prudence or good judgment, integrity through upholding one's beliefs, respectfulness of client's values and beliefs, and benevolence which is a commitment to protect the welfare of others and contribute to the common good (Jordan \& Meara, 1995). There is a shift from focus on the dilemma to appraisal of the acting individual (Freeman, 2000). The model relies on the wisdom of the professionals making an ethical decision rather than specific principles (Garcia et al., 2003). Once again, cultural variables are not considered within this model.

\subsection{Social-constructivist model}

The social-constructivist approach takes into consideration interpersonal processes as well as 
individual and intuitive processes. Cottone (2001) presents one model of the social constructivist approach to decision making. In this model, the first step is to gather information from each party. Next, one assesses the nature of current relationships between the parties involved in the ethical dilemma. Once all sides have been heard, the rehabilitation professional consults with peers and experts for guidance. In solving the dilemma, the professional takes time to negotiate when disagreements arise and works with all parties to come to a consensus regarding the final decision. Decision-making strategies under this model include negotiating, arbitrating, and consensus seeking (Cottone, 2001). According to Garcia et al. (2003) a weakness of this model is that the process of resolution does not include "cultural aspects of the social interaction and structure" (p. 271).

\subsection{Collaborative model}

Davis (1997) proposed a decision-making model based on the values of cooperation and inclusion. His relational model includes a series of four linear steps that include identifying the involved parties, defining the various viewpoints of those involved, developing a solution that is mutually satisfactory to all parties, and implementing individual contributions (Garcia et al., 2003). Although, at first glance, the collaborative model looks a lot like the socialconstructivist model, it differs in that it is structured linearly whereas the social-constructivist model is non-linear and decisions are externally influenced (Garcia et al., 2003). Additionally, social constructivism is based on cognitive theory with ongoing social interaction which reduces the potential for discrepancies while consensus is reached. A strength of the collaborative approach is a group approach to facilitating a mutually satisfactory solution to a dilemma with consideration of individual viewpoints. As with other models, the collaborative model misses opportunities to integrate cultural variables inherent to a relational approach.

\subsection{Integrative model}

Tarvydas' (1998) integrative model builds upon elements of principle and virtue ethics through a four-stage model that integrates reflection, balance, attention to context, and collaboration with rational analysis of the ethical principles underlying the course of action (Garcia et al., 2003). Stages of the model include 1) interpreting the situation through awareness and fact finding; 2) formulating an ethical decision; 3) selecting an action by weighing competing values; and 4) planning and execution of the selected course of action. While the model focuses on the ethical dilemma, the character of the professional, and contextual factors, specific cultural variables are not considered (Garcia et al., 2003).

\subsection{Transcultural integrative model}

The Transcultural Integrative Model (TIM) combines elements of other decision-making models but ensures that cultural influences are considered and addressed at each step in the process. The model is informed by Tarvyda's (1998) Integrative Model through incorporation of its four-step process. In step one, awareness and fact-finding, the rehabilitation professional must first gain and understanding how the dilemma may affect the different stakeholders involved. He or she must also understand how his or her own values, cultural identity, acculturation, and other factors may influence how he or she views the dilemma. By recognizing emotional reactions that may be based on contradictory values, beliefs and/or customs the rehabilitation professional is considering influential aspects that may influence the decisionmaking process (Garcia et al., 2003).

In step two, formulating a course of action is accomplished by analyzing information gathered in step one of the process, reviewing potential laws or regulations that are relevant to the situation, ensuring the course of action aligns with the different worldviews of stakeholders, examining the pros and cons of each course of action, seeking advice from cultural experts, when necessary, and, finally, agreeing upon the best course of action (Garcia et al., 2003).

Step three involves identifying potential challenges such as attitudes of other involved parties. During this step, the rehabilitation professional assesses the readiness of the individual and/or group to handle different scenarios that may arise from the final decision. Contextual influences such as family, systems, laws, and other environmental circumstance that may be influential are considered (Garcia et al, 2003).

In the final step of the model, the decision is implemented, documented, and evaluated. This step includes "securing resources that are culturally relevant for the client and involves developing countermeasures for potential contextual barriers..." (Garcia et al., 2003, p. 274). It is crucial to document each step taken when faced with ethical decisions. This protects the rehabilitation professional and the 
other parties if the decision is disputed. A step-bystep outline of this comprehensive model can be found in Garcia et al., 2003, p. 273.

\section{Increasing multicultural competency in rehabilitation professionals rehabilitation counselor training}

Multicultural Counseling Competence (MCC) involves cultural awareness of oneself and others, cultural knowledge, use of culturally appropriate approaches and interventions, and awareness of power and privilege within the counseling relationship (Areendondo et al., 1996; Matthews et al., 2018; Ratts et al., 2015). Studies show that "MCC is positively correlated with client satisfaction (Constantine, 2007; Kim et al., 2009) and treatment outcomes (Hook et al, 2013; Owen et al., 2011)" (Matthews et al., 2018, p. 131). However, many counselor education programs limit multicultural training to topics of race/ethnicity, gender, and social class (Pieterse et al. 2009). Even programs that focus on the training of rehabilitation professionals often have a lack of emphasis on disability as it intersects with elements of culture (Rivas, 2020; Rivas \& Hill, 2018).

Researchers have reported an urgent need for the integration of multicultural competency training, that includes the culture of disability, into counselor education programs (Chapin et al., 2018; Rivas, 2020; Smith et al., 2008). The Council for Accreditation of Counseling \& Related Educational Programs (CACREP) requires accredited clinical rehabilitation counseling programs to provide evidence of training in diversity, social inequality, oppression, and related concepts with disability included as a unique cultural identity (CACREP, 2017; Rivas, 2020). Many MCC training resources have been updated to include intersecting aspects of cultural identity and advocacy interventions to support marginalized individuals (Ratts et al., 2016). Studies show holistic approaches to rehabilitation counselor training should, in addition to skill development, include focus on diverse types of clients and the broader psychosocial environments in which they live and work (Lee \& Matteliano, 2009; Zanskas \& Strohmer, 2011).

The Center for International Rehabilitation Research Information and Exchange (CIRRIE) developed a curriculum guide to assist faculty in rehabilitation counseling programs to integrate cultural competency education into their curriculums. The authors of the guide, Lee and Matteliano (2009), reference the Campinha-Bacote model for facilitating cultural competence (Campinha-Bacote, 2002). The model consists of five constructs that align with main principles of cultural competency. These include cultural desire, cultural awareness, cultural knowledge, cultural skill, and cultural encounters. Foundational to the model is cultural desire which provides momentum and perseverance for this developmental and ongoing process. Cultural knowledge is conveyed through courses and leads to cultural skill development through clinical experiences that are supervised and evaluated. Cultural encounters, including immersion experiences, allow students to develop confidence when encountering clients from diverse backgrounds (Hunt \& Swiggum, 2007). They should be non-threatening encounters with opportunities for self-reflection through written assignments and group discussions. The purpose is to facilitate awareness and knowledge of a variety of cultures and identify potential biases while developing an appreciation for ethnic diversity (Griswold et al., 2007).

According to Lee and Matteliano (2009), cultural competency education programs should facilitate: 1) integration of cultural competency into existing courses; 2) profession specific rather than generic training; 3) integration of multidisciplinary case studies for analysis of cultural factors; and 4) access to training materials for instructors. Students should be encouraged to engage in self-reflection activities such a writing about cultural experiences and exploring their cultural identity. Self-assessment questionnaires may be utilized to help students understand their knowledge and comfort level with various cultural groups (Spence-Cagle, 2006).

Since there are too many cultural groups and identities to realistically master during a training program, instructors must teach students to assess the cultural identity of their clients and research cultural groups and appropriate and effective treatment strategies as needed. Students must be aware of individual differences that are influenced by acculturation, experiences, and other contextual factors and that many things, including help seeking behaviors, are shaped by cultural context (Menjivar, 2006). Concepts of empowerment, self-determination, individualization, and equality should be incorporated into training curricula and students should be educated about the compounding effects that multiple minority status may have on an individual (Lee \& Matteliano, 2009). If cultural knowledge is not considered within the context of unique experiences and circumstances, stereotyping may occur (Juckett, 2005). 


\section{Conclusion}

It is important to recognize that there is no cookiecutter, one-size-fits all approach to working with individuals. Rehabilitation professionals must adapt approaches to align with the cultural perspectives, values, and needs of each person served. Due to the large variety of cultures and cultural identities, cultural learning is ongoing. Participation in professional organizations, conferences, and continuing education are a few of the avenues for ongoing multicultural learning.

Above all other aspects of ethical practice, rule number one is Do No Harm. It is the ethical responsibility of the rehabilitation professional to provide services and supports in a multiculturally competent manner. The information, models, and practices presented provide guidance for structuring rehabilitation counseling program curricula to facilitate development of multicultural knowledge and skills in future rehabilitation professionals and, in turn, multicultural competence when these rehabilitation professionals work with diverse clientele.

\section{Acknowledgments}

The author would like to acknowledge and reflect on the many racially and culturally charged events and tragedies that continue to occur around the country and the globe and the unrest we are witnessing in our own communities. These challenging times provide an opportunity for all of us to demonstrate an active commitment to creating a civil, humane, and compassionate society in which discrimination, of any kind, is not tolerated. Most in this field maintain a deep commitment to diversity and inclusion. We have no tolerance for racism, oppression, or discrimination, and we value the respectful treatment of all members of our society. These events should prompt us to pause, reflect and act. We must band together, as a community, to expand upon and enhance efforts to promote inclusion, opportunity, and civility.

\section{Conflict of interest}

The author declares that there is no conflict of interest.

\section{References}

American Counseling Association. (2014). 2014 ACA code of ethics. Retrieved December 22, 2020, from https:// www.counseling.org/docs/default-source/default-documentlibrary/2014-code-of-ethics-finaladdress.pdf.

Association for Multicultural Counseling and Development (AMCD). (2015). Multicultural and Social Justice Counseling Competencies. Retrieved January 1, 2021, https://www.coun seling.org/docs/default-source/competencies/multiculturaland-social-justice-counseling-competencies.pdf?sfvrsn=20.

Anon. (2021). The cultural iceberg. Retrieved January 12, 2021, from https://adeaconsmusing.ca/wp-content/uploads/ 2015/10/151015.ucc_.culture.iceberg.pdf.

Arredondo, P., \& Toporek, R. (2004). Multicultural counseling competencies in ethical practice. Journal of Mental Health Counseling, 26, 44-55.

Arredondo, P., Toporek, R., Brown, S. P., Jones, J., Locke, D. C., Sanchez, J., \& Stadler, H. (1996). Operationalization of the multicultural competencies. Journal of Multicultural Counseling and Development, 24, 42-78.

Beveridge, S., Karpen, S., Chan, C., \& Penrod, J. (2016). Application of the KVI-R to Assess Current Training Needs of Private Rehabilitation Counselors. Rehabilitation Counseling Bulletin, 59(4) 213-223. https://doi.org/10.1177/0034 355215590770 .

Budiman, A. (2020). Americans are more positive about the long-term rise in U.S. racial and ethnic diversity than in 2016. Retrieved January 1, 2021, from https://www.pewre search.org/fact-tank/2020/10/01/americans-are-more-positive -about-the-long-term-rise-in-u-s-racial-and-ethnic-diversitythan-in-2016/.

Campinha-Bacote, J. (2002). The process of cultural competence in the delivery of healthcare services: A model of care. Journal of Transcultural Nursing, 13(3), 181-184.

Chapin, M., McCarthy, H., Shaw, L., Bradham-Cousar, M., Chapman, R., Nosek, M., Peterson, S., Yilmaz, Z., \& Ysasi, N. (2018). Disability-related counseling competencies. Alexandria, VA: American Rehabilitation Counseling Association, a division of ACA.

Cilluffo, A., \& Cohn, D. (2019). 6 demographic trends shaping the U.S. and the world in 2019. Retrieved January 10, 2021, from https://www.pewresearch.org/fact-tank/2019/04/ 11/6-demographic-trends-shaping-the-u-s-and-the-world-in$2019 /$.

Commission on Rehabilitation Counselor Education (CRCC). (2017). Code of Professional Ethics for Rehabilitation Counselors. Retrieved January 1, 2021, from https://www. crccertification.com/filebin/Ethics_Resources/CRCC_Code_ Eff_20170101.pdf.

Council for Accreditation of Counseling \& Related Educational Programs (CACREP). (2017). July 2017 Announcement [Press release]. Retrieved from https://www.cacrep. org/home/cacrepcpre-updates/.

Constantine, M. G. (2007). Racial microaggressions against African American clients in across-racial counseling relationship. Journal of Counseling Psychology, 54, 1-16. https://doi. org/10.1037/0022-0167.54.1.1.

Cottone, R.R. (2001). A social constructivism model of ethical and professional issues in counseling. Journal of Counseling and Development, 79, 39-45. 
Culbertson, G. (2021). How can an iceberg help us understand culture? Retrieved January 1, 2021, from http://home. snu.edu/ hculbert/iceberg.htm.

Davis, A. H. (1997). The ethics of caring: A collaborative approach to resolving ethical dilemmas. Journal of Applied Rehabilitation Counseling, 28(1), 36-41.

Diversity and Multiculturalism. (2016). University of Minnesota Libraries Publishing Edition. Retrieved January 1, 2021, from https://open.lib.umn.edu/humanresourcemanagement/chapter/ 3-1-diversity-and-multiculturalism/.

Forester-Miller, H., \& Davis, T. E. (2016). Practitioner's guide to ethical decision making (Rev. ed.). Retrieved from http:// www.counseling.org/docs/default-source/ethics/practioner'sguide-toethical-decision-making.pdf.

Freeman, S. J. (2000). Ethics: An introduction to philosophy and practice. Wadsworth/Thompson Learning.

Frey, W. (2020). The nation is diversifying even faster than predicted, according to new census data. Retrieved January 1, 2021, from https://www.brookings.edu/research/new-censusdata-shows-the-nation-is-diversifying-even-faster-than-pre dicted/.

Garcia, J. G., Cartwright, B., Winston, S. M., \& Borzuchowska, B. (2003). A transcultural integrative model for ethical decision making in counseling. Journal of Counseling \& Development, 81(3), 268-277. http://dx.doi.org/10.1002/j.15566678.2003.tb00253.x.

Griswold, K., Zayas, L., Kernan, J. B., \& Wagner, C. M. (2007). Cultural awareness through medical student and refugee patient encounters. Journal of Immigrant Health, 9, 55-60.

Hays, D. G. \& Erford, B. T. (2018). Developing Multicultural Counseling Competence: A Systems Approach (3rd ed.). Pearson Education, Inc.

Hook, J. N., Davis, D. E., Owen, J., Worthington, E. L., \& Utscy, S. O. (2013). Cultural humility: Measuring openness to culturally diverse clients. Journal of Counseling Psychology, 60, 353366. https://doi.org/10.1037/a0032595.

Horowitz, J. M. (2019). Americans see advantages and challenges in country's growing racial and ethnic diversity. Retrieved January 1, 2021, from https://www.pewsocialtrends.org/2019/ 05/08/americans-see-advantages-and-challenges-in-countrysgrowing-racial-and-ethnic-diversity/.

Hunt, R., \& Swiggum, P. (2007). Being in another world: Transcultural experiences usingservice learning with families who are homeless. Journal of Transcultural Nursing, 18(2), 167-174.

Jordan, A. E., \& Meara, N. M. (1995). Ethics and the professional practice of psychologists: The role of virtues and principles. In D. N. Bersoff (Ed.), Ethical conflicts in psychology (pp. 135-141). American Psychological Association.

Juckett, G. (2005). Cross-cultural medicine. American Family Physician, 72(11), 2267-2275.

Kim, B. S. K., Ng, G. F., \& Ahn, A. J. (2009). Client adherence to Asian cultural values, factors in counseling, and session outcome with Asian American clients at a university counseling center. Journal of Counseling and Development, 87, 131-142.

Kitchener, K. S. (1984). Intuition, critical evaluation and ethical principles: The foundation for Ethical decisions in counseling psychology. Counseling Psychologist, 12, 43-55.

Lee, G. K. \& Matteliano, M. A. (2009). A guide to cultural competence in the curriculum: Rehabilitation Counseling. Retrieved January 1, 2021, from http://cirrie-sphhp.webapps. buffalo.edu/culture/curriculum/guides/rc.pdf.
Limbong, A. (2020). Microaggressions are a big deal: How to talk them out and when to walk away - Interview with Kevin Nadal. Retrieved January 1, 2021, from https://www. npr.org/2020/06/08/872371063/microaggressions-are-a-bigdeal-how-to-talk-them-out-and-when-to-walk-away.

Matthews, J. J., Barden, S. M., \& Sherrell, R. S. (2018). Examining the relationships between multicultural counseling competence, multicultural self-efficacy, and ethnic identity development of practicing counselors. Journal of Mental Health Counseling, 40, 129-141.

Menjívar, C. (2006). Liminal legality: Salvadoran and Guatemalan immigrants' lives in the United States. The American Journal of Sociology, 111(4), 999-1037.

Owen, J., Leach, M. M., Wampold, B., \& Rodolfa, E. (2011). Multicultural approaches in psychotherapy: A rejoinder. Journal of Counseling Psychology, 58, 22-26. https:// doi.org/10.1037/a0022222.

Papadopoulos, I., Tilki, M., \& Taylor, G. (1998). Transcultural care: A guide for health care professionals. London Quay Books. Wilts.

Pieterse, A. L., Evans, S. A., Risner-Butner, A., Collins, N. M., \& Mason, L. B. (2009). Multicultural competence and social justice training in counseling psychology and counselor education. A review and analysis of a sample of multicultural course syllabi. The Counseling Psychologist, 37(1), 93-115.

Poston, D. L. (2020). 3 ways that the U.S. population will change over the next decade. Retrieved January 1, 2021, from https://www.pbs.org/newshour/nation/3-ways-that-theu-s-population-will-change-over-the-next-decade.

Ratts, M. J., Singh, A. A., Nassar-McMillan, S., Butler, S. K., \& McCullough, J. R. (2016). Multicultural and social justice counseling competencies: Guidelines for the counseling profession. Journal of Multicultural Counseling and Development, 44(1), 28-48. https://doi.org/10.1002/jmcd. 12035.

Ratts, M. J., Singh, A. A., Nassar-McMillan, S., Butler, S. K., McCullough. J. R" \& Hipolito Delgado, C. (2015). Multicultural and social justice counseling competencies. Alexandria, VA: Association for Multicultural Counseling and Development.

Rivas, M. (2020). Disability in counselor education: Perspectives from the United States. International Journal for the Advancement of Counselling, 42, 366-338. https://doi.org/10. 1007/s10447-020-09404-y.

Smith, L., Foley, P., \& Chaney, M. (2008). Addressing classism, ableism, and heterosexism in Counselor education. Journal of Counseling \& Development, 86, 303-309.

Spence Cagle, C. (2006). Student understanding of culturally and ethically responsive care:Implications for nursing curricula. Nursing Education Perspectives, 27(6), 308-314.

Steemit. (2021). National Culture - Individualism VS Collectivism around the World. Retrieved January 1, 2021, from https://stee mit.com/philosophy/@lifenbeauty/national-culture-individua lism-vs-collectivism-around-the-world.

Tarvydas, V. M. (1998). Ethical decision-making processes. In R. R. Cottone \& V. M. Tarvydas (Eds.), Ethical and professional issues in counseling (pp. 144-154). Prentice Hall.

U.S. Census Bureau QuickFacts: United States. (2021). Retrieved January 1, 2021, from https://www.census.gov/quickfacts/ fact/table/US/PST045219.

What's the Difference Between a Diverse and a Multicultural World? (2014). Retrieved 23 June 2020, from http://hybridpar 
enting.org/whats-the-difference-between-a-diverse-worldand-a-multicultural-world/.

Zanskas, S., \& Leahy, M. (2007). Preparing rehabilitation counselors for private sector practice within a CORE accredited generalist education model. Rehabilitation Education, 21, 205214 .
Zanskas, S., \& Strohmer, D. C. (2011). The work environment of the private-for-profit rehabilitation counselor. Journal of Rehabilitation, 77, 13-22. 